\title{
Modelling and Design of Five Parameter Single Diode Photovoltaic Model with Artificial Intelligent MPPT Power System
}

\author{
A. Chandramouli, V. Sivachidambaranathan, R.Arulmurugan
}

\begin{abstract}
In this article, an improved single diode Photo Voltaic mathematical system with novel Fuzzy Logic Control (FLC) based maximum power extraction approach was developed. The photovoltaic module voltage versus current characteristics derivation were developed and it's utilized to extract the photovoltaic module unknown arguments via as saturation current, light generated current, shunt and ideality factor, series resistance at reference. The various mathematical models are utilized to determine the photovoltaic system arguments at reference circumference by acquainting equations to calculate the value of resistance in series and shunt. The production of highest power of PV modules were equated with dissimilar manufactured $P V$ model with various environmental conditions. The percentage relative error and highest power is computed and compared with previous models in the survey for dissimilar photovoltaic modules. Further, in this paper added with improved Perturb and Observe $(P \& O)$ based FLC control approach utilized to extract the highest energy from solar panel. The output of the developed system exposes the good performance during steady state period and transient periods. Moreover to confirm the developed photovoltaic model matches exactly with that of Sandia PV module.
\end{abstract}

Keywords

Fuzzy Logic Controller, Improved Perturbation and Observation, Maximum energy extraction

\section{INTRODUCTION}

Recent days nonconventional energy sources or called renewable energy source plays a major role to compensate the energy shortage, reduce the fossil fuels consumption and global warming, etc. The renewable energy source is uninterrupted and available all days throughout of the years, particularly solar photovoltaic is less maintains and long life system [1]. Nowadays developed and developing countries concentrate to implemented the solar photovoltaic system to roof top, road, roof of aeroplane, etc[2][3]. to reduce the dependency of conventional energy source[4]. It's help to reduce the erecting grid system in rural and hills place to give source. Out of all renewable energy source the solar photovoltaic system is available in all place associated to different nonconventional source because the implementation require less space, less maintains and investment cost compare to other source like wind energy

system[5]-[9]. The major challenge is the photovoltaic

Revised Version Manuscript Received on August 19, 2019.

A. Chandramouli, Dept. of Electrical, Sathyabama Institute of Science Technology, Chennai, Tamilnadu, India.(email: chandersrec@gmail.com)

V. Sivachidambaranathan, Dept. of Electrical, Sathyabama Institute of Science Technology, Chennai, Tamilnadu, India.(email: sivachidambaram_eee@yahoo.com)

R.Arulmurugan, Dept. of Electrical Engineering, Sanjivani College of Engineering, Kopargaon, Maharashtra, India.(email: arul.lect@gmail.com) system is nonlinear nature so its require the proper power converter like DC to DC converter and Maximum Power Point Tracking (MPPT) controller and inverter system uses to reduce the losses and connect to the grid for excess of the power supply[6][7]. In generally, analysis of the solar photovoltaic module is required to predict the performance output while connecting it with the present grid structure[8]. The smart grid is integrated with all grid supply, it work in slated as well integrated with main grid system wherever and whenever required[10]. The eighty percent of investment cost consumes solar panel so track the maximum power to utilize the panel system efficiently[11]. The exact mathematical system of solar photovoltaic model uses to track the highest energy underneath various environment situations [12].

The MPPT approaches contains numerous methods or algorithms that are helpful to discovery the peak power point underneath dissimilar environment circumstances. Some of the algorithm approaches are simple, less cost and more accurate. Such as current feedback, voltage feedback. Some approach take little oscillation on peak point such as incremental conductance, perturbation and observation. These methods are little bit complexity, required sensor, range of operation, speed of convergence, able to detect the multiple local maximum. [13]-[20]. Out of all the methods the perturbation and observation are simple and curious look at the recommended point of view because simplicity and easy to implemented [14]-[16].

The perturb and observe approach is perturbation in the functioning voltage of the photovoltaic array. The perturbation and observation approach cannot match the panel voltage with actual result of voltage in peak point period. The output of perturbation and observation are not accurate enough because oscillations take place at the point of MPP which consequently waste the energy [15]. By reducing the perturbation step size simultaneously the oscillation can be dropped but mean while a lower perturbation size reduces the speed of tracing of maximum power points. Hence, this method is fail under rapidly varying atmospheric situations[17]. The artificial intelligent techniques like neural network and Fuzzy logic controllers have the merits of functioning with imprecise inputs not required an accurate mathematical model and handling 


\section{MODELLING AND DESIGN OF FIVE PARAMETER SINGLE DIODE PHOTOVOLTAIC MODEL WITH ARTIFICIAL INTELLIGENT MPPT POWER SYSTEM}

nonlinearity [13],[18].

This paper presents a new FLC based Modified Perturb and Observe (MPO) technique for MPE standalone photovoltaic system. The designed MPE tracking is capable of exploiting the merits of the $\mathrm{P} \& \mathrm{O}$ process and eradicates its problems. The MPE is analysed by converting the improved $\mathrm{P} \& \mathrm{O}$ algorithm into 37 fuzzy rules after the controller two inputs and single output have been divided to seven fuzzy subsets. As the designed technique always transfers extreme power from photovoltaic arrays, it enhances the number of photovoltaic modules. The designed system is instigated in real-time using microcontroller board[19].

An accurate solar photovoltaic system is uses to develop an effective model for photovoltaic researcher. The developers provides the name plate sheet of the module arguments at typical test result[3]. The two diode model is more complexity that's why single diode model system is familiarly considered by most of the researcher [5]. This article shows the modelling of five parameter diode system of photovoltaic model and FLC MPPT has been developed. The developed model is regulate the enactment of the system with dissimilar atmospheric situation.

\section{EQUIVALENT DIODE MODEL OF PV SYSTEM}

The following Fig.1 illustrate the one diode system of photovoltaic model. Which contains of ideality factor (A), shunt (Rsh), current generation through light, current of saturation and series connection of resistance. Mathematical model of module voltage versus current characteristics equation is derived as follows [11],[12]:

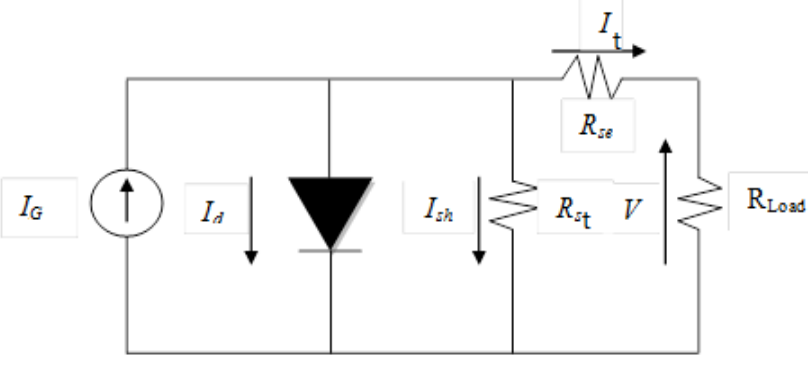

Fig 1. One diode system of PV module

$$
\begin{aligned}
& I_{t}=I_{g}-I_{s t}\left[e^{I R e+V) / N t N S}-1\right]-\frac{I_{e}+V}{R_{s t}} \\
& V_{t}=\frac{\mathrm{kAT}_{\mathrm{c}}}{\mathrm{q}}
\end{aligned}
$$

In the equation the negative sign term is neglected the current flow in diode and rewritten as shows:

$$
I_{t}=I_{g}-I_{s t} e^{I R e+V) / V t N S}-\frac{I R_{\theta}+V}{R_{s t}}
$$

\section{IMPROVED P\&O BASED FLC MPPT APPROACH}

A triangular reference signal is likened with the yield signal of fuzzy voltage reference to deliver a probably zero error signal. The fuzzy rules are derived from improved $\mathrm{P} \& \mathrm{O}$ approach. The adaptive reference single is varying the according to the climatic situations. The boost converter feed the battery load with the most suitable power [14].

The proposed entire schematic diagram is show in Fig.2 boost DC to DC conversion together with the maximum power extracting and the fuzzy controller. The Mamdani technique approach used to develop FLC system. The FLC system includes the membership function and design of the rules will be detailed in the next sections. The Pulse Width Modulation varies its duty-cycle pulse according to the control signal[12],[17].

In fuzzy controller proposal, one should detect the foremost control variables and regulate the sets that define the values of individually linguistic variable. The developed $\mathrm{P} \& \mathrm{O}$ searching algorithm is calculated to attain the merits of conventional $\mathrm{P} \& \mathrm{O}$ simplicity and eradicate all aforementioned disadvantages[18][19]. The change in photovoltaic output voltage and the change in photovoltaic array output power are the two input of the modified FLC approach. The increment of the reference output voltage of the FLC where fed into discrete PI controller through Pulse Width Modulation (PWM) control box to produce the pulse. The two inputs and single output of the FLC are given in the equations from (31) to (33)
Del_P= $\mathrm{P}(\mathrm{k})-\mathrm{P}(\mathrm{k}-1)$
Del_V= V(k)- V(k 1)

Del_Vref $=$ Vref $(\mathrm{k})-\operatorname{Vref}(\mathrm{k} 1)$

The merits of this improved in perturb and observe is that the yield of the fuzzy based control changes the reference voltage only. Hence, the duty cycle of the DC to DC boost converter can further be regulated using specific controller. Moreover, the boost converter controller ensures that the photovoltaic output power does not deviate from the possible power point during changing weather situations or variable load.

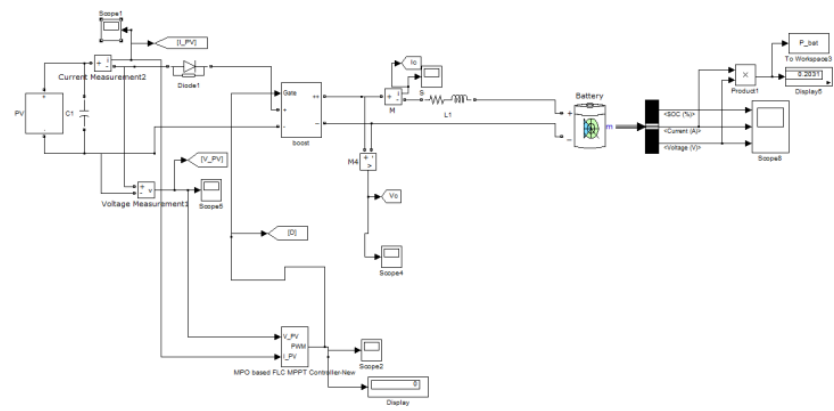

Fig.2 proposed overall setup of the PV system

The variables of the input logic are allocated into seven fuzzy subsets which are: negative big (NB), positive big $(\mathrm{PB})$, zero (Z), (PS) positive small, (NS) negative small, positive medium (PM), negative medium (NM). These seven fuzzy subsets for two input variables can produce forty-nine FLC rules, but the zero membership rules are shortened in one rule which is only making total of thirty-seven rules, instead of forty-nine[16]. The Membership Functions (MF) of the output variables are nine-term fuzzy sets with trapezoidal shapes and classical triangular, positive double big(PBB), negative double big(NBB), positive medium (PM), (NM) negative medium, (NS) negative small, positive small (PS), (Z) zero, (PB) positive big, negative big (NB), and positive very small (PSL), negative very small (NSL). The fuzzy technique utilized here is Mamdani approach, 
where the max-min composition method is utilized for the inference of fuzzy logic system. The centre-of-gravity defuzzification approach is used to the fuzzy subset reference voltage that changes to real numbers as offered in equation (34).

$$
\Delta V_{\text {ref }}=\frac{\sum_{i}^{n} \Delta V_{r e f i} \mu\left(\Delta V_{r e f i}\right)}{\sum_{i}^{n} \mu\left(\Delta V_{r e f i}\right)}
$$

Where Vref is the FLC output, Vrefi is the output MF.

The fuzzy rules impersonate the conduct of improved perturb and observe technique. The fuzzification of the perturbation and observation technique with the rules is revealed in Fig.3. The shapes and fuzzy subset partitions of the MF in both output and two inputs exposed in Fig.4 depend on the behaviour of the controller in and out signals. The fuzzy logic control manages variable step size to decrease or increase the reference voltage; hence, the tracking period becomes little and the framework execution during steady-state situations is much better than with traditional perturb and observe approach. Furthermore, the zero -MF keeps the scheme in the steady-state without fluctuations once it attains the MPP; this zero -MF is considered an overtaking on perturb and observe approach in solving the issue of fluctuation. After Matlab simulation of the improved perturb and observe calculation with boost dc to dc converter the error (del_P) and change of error (del_V) is calculated and normalized between ( -10 to 10$),(-0.5$ to 0.5$)$ respectively. The change in voltage reference (del_Vref) is normalized (-10 to 10$)$. The fuzzy membership function utilized as a part this design is mamdhani method. In the new fuzzy based MPPT Gaussian surface fuzzy membership function is utilized. The triangular fuzzy MF for two input and single yield are illustrated in the rule viewer and the corresponding surface diagram is revealed in following Fig.5 and Fig.6 separately.

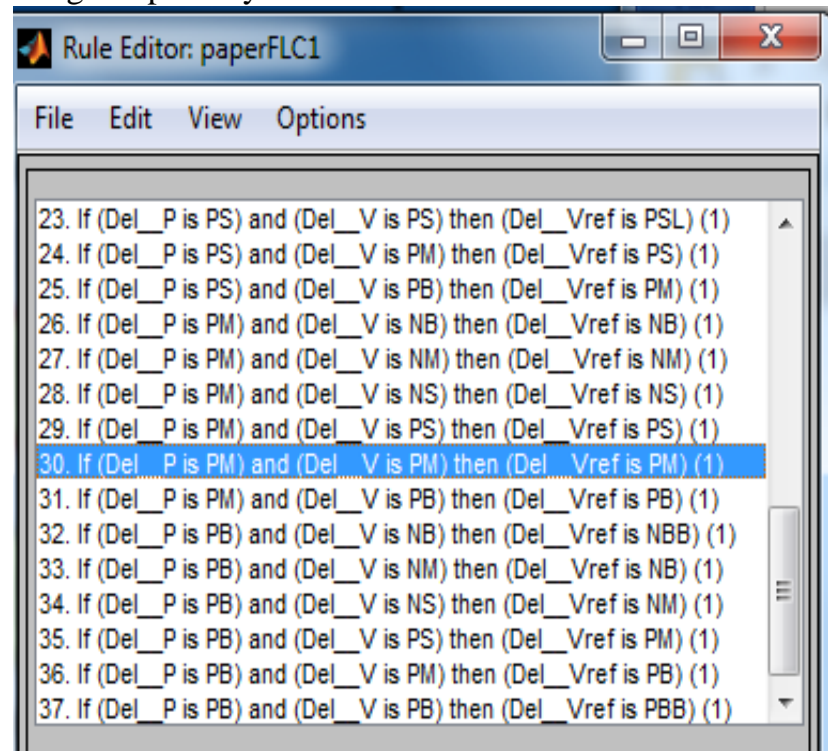

Fig.3 Fuzzification of the improved perturb and observe rules

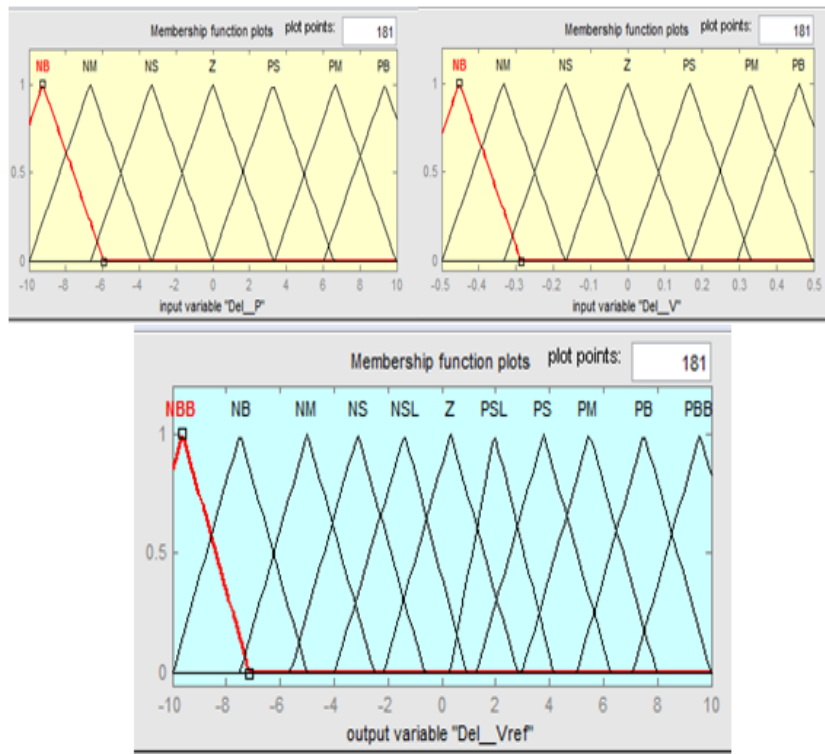

Fig.4 MF of FLC MPPT approach (a) Del_P (b) Del_V (c) Del_Vref

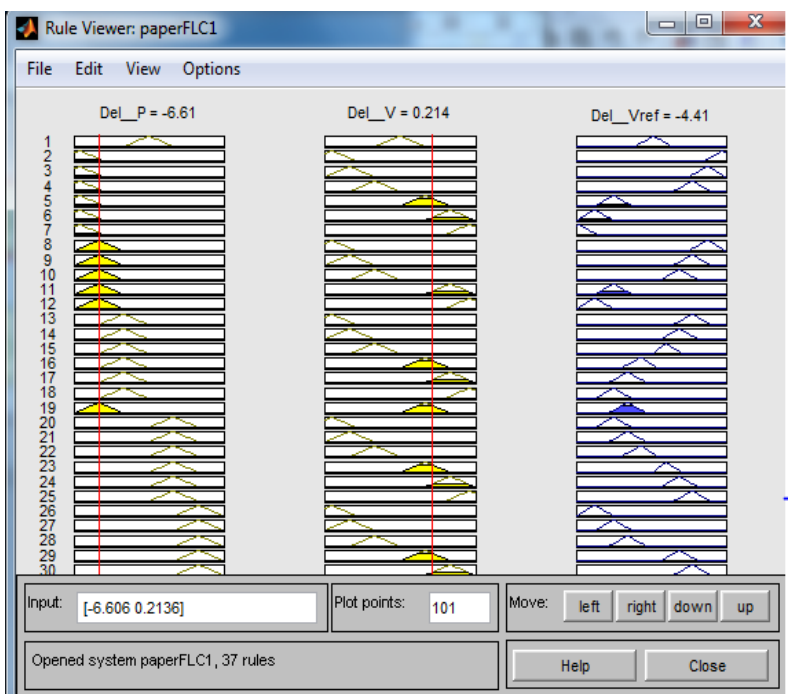

Fig.5 Rule viewer of the designed new FLC

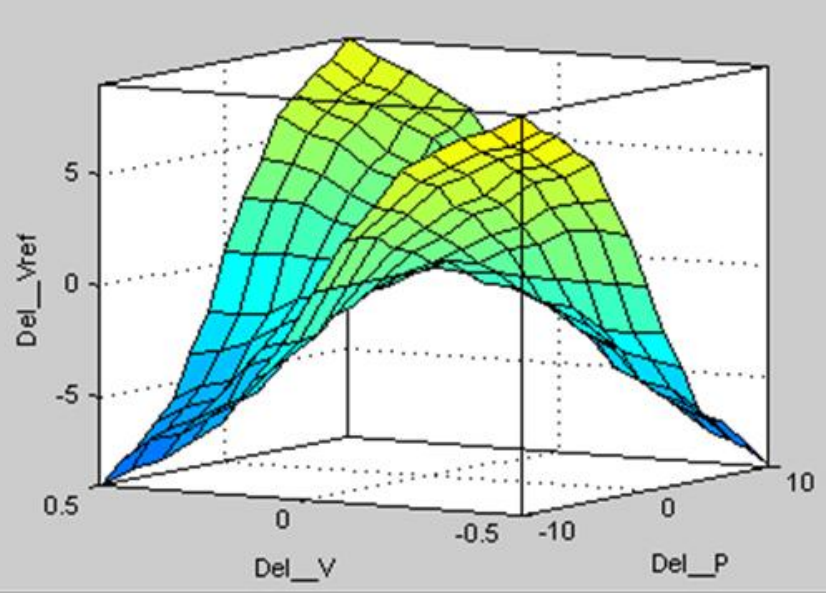

Fig.6 Surface view of proposed FLC system 


\section{MODELLING AND DESIGN OF FIVE PARAMETER SINGLE DIODE PHOTOVOLTAIC MODEL WITH ARTIFICIAL INTELLIGENT MPPT POWER SYSTEM}

\section{RESULT ANALYSIS AND SUMMARY}

Four dissimilar solar PV datasheet are chosen for conforming the designed photovoltaic model. The solar PV modules multi, mono Thin film) are utilized to analysis the enactment of the designed system at normal condition with changing $G$ and constant $T$ conditions [8]. In Table I and Table II, highest energy exhausting the developed photovoltaic system has been analysed and the resultants were matched by the Kulaksiz ANFIS and Sandia photovoltaic system model [8].

Table I. Developed model Kulaksiz and Sandia maximum power extraction model at $\mathrm{Tc}=25^{\circ} \mathrm{C}$ with variation of $\mathbf{G}$.

\begin{tabular}{|c|c|c|c|c|c|}
\hline \multirow[b]{2}{*}{$\mathrm{G}\left(\mathrm{W} / \mathrm{m}^{2}\right)$} & \multirow{2}{*}{$\begin{array}{c}\text { Maximum } \\
\text { power of } \\
\text { Sandia model } \\
\text { (W) }\end{array}$} & \multicolumn{2}{|c|}{$\begin{array}{c}\text { Kulaksiz ANFIS peak power } \\
\text { Model }\end{array}$} & \multicolumn{2}{|c|}{ Developed model } \\
\hline & & $\begin{array}{l}\text { Peak } \\
\text { power } \\
\text { (W) }\end{array}$ & $\begin{array}{c}\text { error in } \\
\text { percentage }\end{array}$ & $\begin{array}{l}\text { Peak power } \\
\text { (W) }\end{array}$ & error relative (\%) \\
\hline 1000 & 69.96 & 69.56 & 0.57 & 70.15 & -0.27 \\
\hline 800 & 56.64 & 55.86 & 1.38 & 55.74 & 1.59 \\
\hline 600 & 42.53 & 41.63 & 2.12 & 41.16 & 3.22 \\
\hline 400 & 28.12 & 27.15 & 3.45 & 26.64 & 5.26 \\
\hline 200 & 13.81 & 12.74 & 7.75 & 12.52 & 9.34 \\
\hline
\end{tabular}

Table II. Comparison of developed PV model with the experimental power at $\mathrm{Tc}=25^{\circ} \mathrm{C}$ with variation irradiation conditions.

\begin{tabular}{|c|c|c|c|c|c}
\hline $\begin{array}{c}\mathbf{G} \\
\text { (irradiance } \\
\left(\mathbf{W} / \mathbf{m}^{\mathbf{2}}\right)\end{array}$ & $\begin{array}{c}\text { Calculated } \\
\text { power by } \\
\text { Xu et al } \\
\text { model } \\
\text { (in W) }\end{array}$ & $\begin{array}{c}\text { Investigated } \\
\text { power (W) }\end{array}$ & $\begin{array}{c}\text { Developed syst. } \\
\text { determined } \\
\text { power (W) }\end{array}$ & $\begin{array}{c}\% \\
\text { Error in } \\
\text { percentage }\end{array}$ & $\begin{array}{c}\text { Deviation } \\
\text { of } \\
\text { Power } \\
\text { from Xu } \\
\text { et al } \\
\text { model }\end{array}$ \\
\hline 200 & & & & & 6.04 \\
300 & 53.96 & 34.15 & 31.91 & 6.56 & 4.58 \\
400 & 69.61 & 51.67 & 49.41 & 4.37 & 3.39 \\
500 & 87.46 & 86.85 & 85.28 & 1.81 & 2.49 \\
600 & 105.26 & 105.02 & 103.40 & 1.54 & 1.77 \\
700 & 122.96 & 122.33 & 121.53 & 0.65 & 1.16 \\
800 & 140.55 & 140.48 & 139.60 & 0.63 & 0.68 \\
900 & 158.00 & 157.47 & 157.57 & -0.06 & 0.27 \\
1000 & 175.00 & 175.00 & 175.37 & -0.21 & -0.21 \\
\hline
\end{tabular}

The results shows the higher deviation error relation of SP70 and TDP125 at $200 \mathrm{~W} / \mathrm{m} 2$ irradiation condition compared with other irradiation. The output of the developed PV system beneficial compared with ANFIS kulksiz model system [8].

Voltage vs. current and Voltage vs. power curves for mono crystalline Shell SP70, and TDP125 (poly crystalline) photovoltaic modules at STC $25^{\circ} \mathrm{C}$ with dissimilar $\mathrm{G}$ viz as 200, 400, 600,800 and $1000 \mathrm{~W} / \mathrm{m} 2$ are illustrated in Fig.7, and Fig. 8 correspondingly. The illustrated diagram shows the voltage vs current and voltage vs power curves of developed PV MPP module with Kulaksiz ANFIS and Sandia model. Further the aim of this article to extract the peak power under varying climatically situation and extract the maximum power during change of weather condition. The developed model exactly matches with the reference model of sandia and kulkksiz [8]. At very low irradiation condition deviation take place at mono technology PV model. Therefore the developed model is working to predict the enactment of the system effectively and precisely.

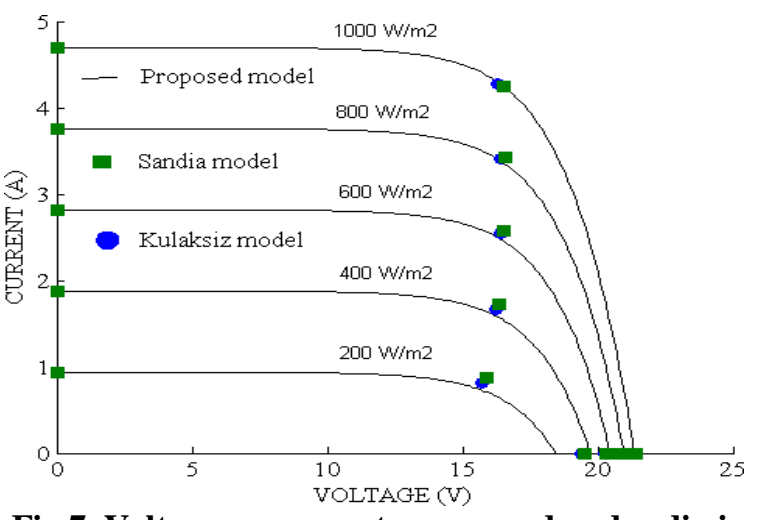

Fig.7. Voltage vs. current curves and under dissimilar $\mathrm{G}$ conditions at $25^{\circ} \mathrm{C}$

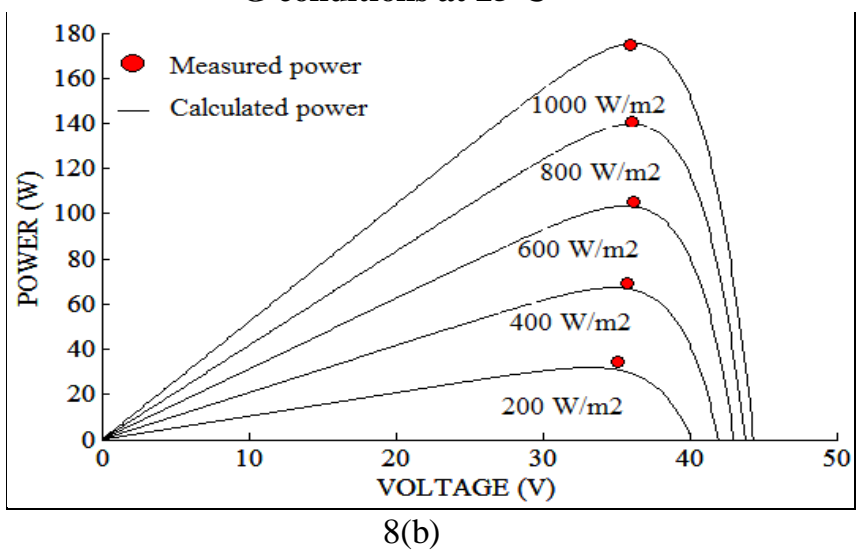

Fig.8 Voltage vs. power plot for TDP125 module, under various $\mathrm{G}$ conditions at $25^{\circ} \mathrm{C}$

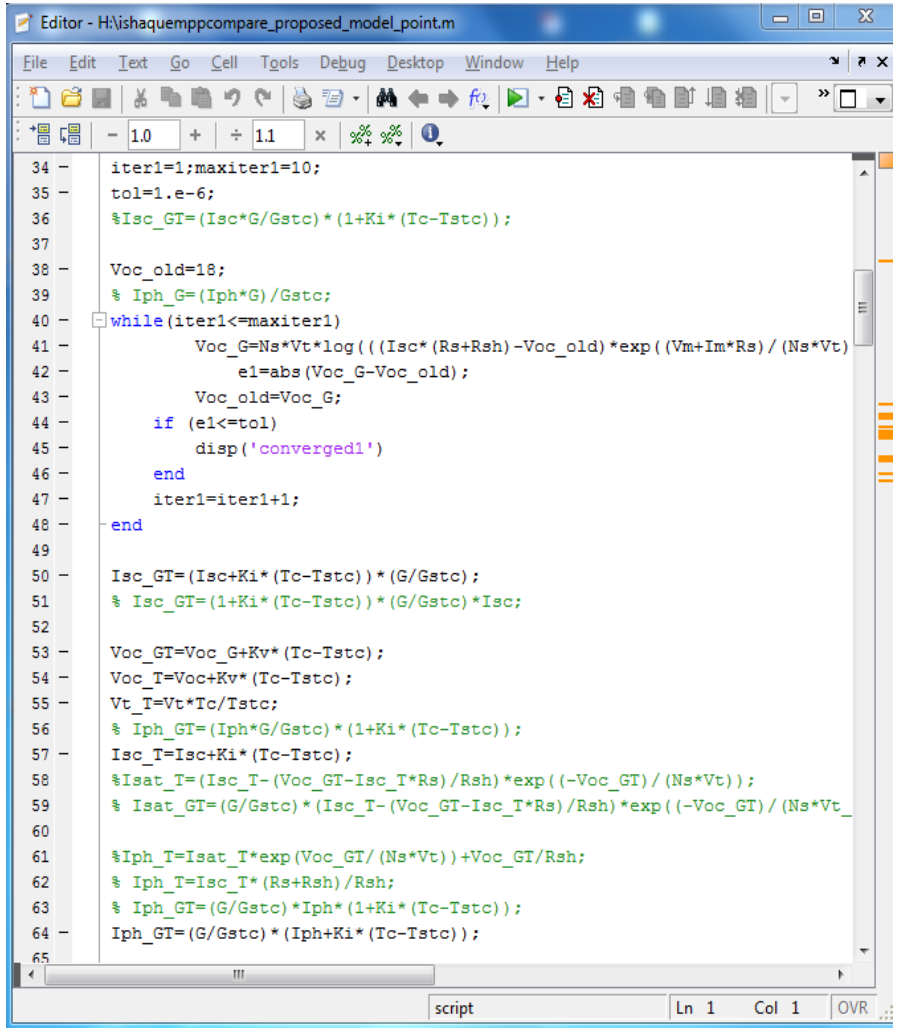

Fig.9 Screenshots of the designed PV module

Published By: 


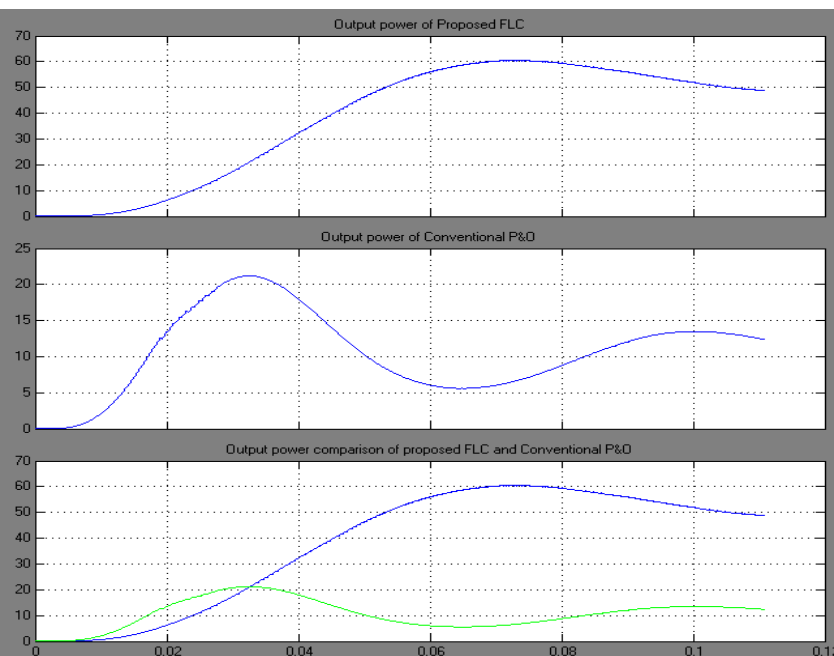

Fig.10 Output power comparison of proposed FLC and conventional P\&O technique (a) proposed FLC (b) Conventional FLC (c) Combined system

Fig.9 displays the screenshots of developed photovoltaic model in MATLAB tool. Comparison of proposed MPO based fuzzy control and conventional $\mathrm{P} \& \mathrm{O}$ as demonstrated in Fig.10. In the figure confirm that the developed FLC MPPT system produce less oscillation when irradiation variation, in the current during 0.04 to 0.07 seconds the conventional $\mathrm{P} \& \mathrm{O}$ produce more oscillation but proposed system doesn't produce any oscillation when irradiation was varied.

\section{CONCLUSION}

This article, an improvement of single diode photovoltaic model with FLC based MPPT approach has been developed. The designed photovoltaic model is uses to predict the highest power for dissimilar photovoltaic technologies and enhanced FLC MPPT approach uses to extract the highest power from solar PV source. A numerical and analytical approaches viz SUR and GS are utilized to calculate the developed model arguments at normal test situation by entering developed modelling. Maximum power of dissimilar photovoltaic system models produced by different materialogy at various circumference circumstances is calculated by peak current and peak voltage. The precision of the developed photovoltaic system is examined against hardware data which is stated in the survey were comparing the relative error. Relative error is found to be less than the proposed model when compared with Kulaksiz ANFIS model and Sandia model. In generally, PV two diode model affords best results than PV single diode system but in the proposed PV single diode system illustrated good correlation with PV two diode model. In addition with in this paper added new FLC MPPT system uses to track the highest power from photovoltaic module during varying climatic condition. Hence, the developed single diode model system is very valuable device for photovoltaic developer and researcher

\section{REFERENCES}

1. Serban E, Serban H. "A Control Strategy for a Distributed Power Generation Microgrid Application with Voltage and Current Controlled Source Converter". IEEE Trans. Power Electr 2010; 25: 2981 - 2992.

2. Kashif I, Zainal S, Hamed T. "Simple, fast and accurate two-diode model for photovoltaic modules". Sol Energ Mat Sol C 2011; 95: 586 - 594.

3. Ma T, Yang H, Lu L. "Development of a model to simulate the performance characteristics of crystalline silicon photovoltaic modules/strings/arrays", Sol Energy 2014; 100: 31 - 41 .

4. R. Arulmurugan, "Photovoltaic powered transformer less hybrid converter with active filter for harmonic and reactive power compensation", ECTI Transactions on Electrical Engineering, Electronics, and Communications, Vol.16, No.2, PP.44-51, August 2018

5. Kashif I, Zainal S and Syafaruddin, "A comprehensive MATLAB Simulink PV system simulator with partial shading capability based on two-diode model", Sol energy 2011; 85: 2217 - 2227.

6. Sera D, Teodorescu R, Rodriguez P. "PV panel model based on datasheet values", In: IEEE 2007 International Symposium on Industrial Electronics; 4-7 June 2007; Vigo, Spain: IEEE. pp. 2392 - 2396.

7. Lo Brano V, Ciulla G. "An efficient analytical approach for obtaining a five parameters model of photovoltaic modules using only reference data", Applied Energy 2013; 111: 894-903.

8. R.Arulmurugan, et al, "Tracking of photovoltaic power system with new Fuzzy Logic Control strategy", Journal of Electrical Engineering (JEE), Volume 14, 2014-Edition:4 , pp.1-10. ISSN 1582-4594.

9. Bai J, Liu S, Hao Y, Zhang Z, Jiang M, Zhang Y. "Development of a new compound method to extract the five parameters of PV modules", Energy Convers Manage 2014; 79: 294 - 303.

10. Kulaksiz AA. "ANFIS-based estimation of PV module equivalent parameters: application to a stand-alone PV system with MPPT controller", Turk J Elec Eng \& Comp Sci 2013; 21: $2127-2140$.

11. Ghani F, Duke M. "Numerical determination of parasitic resistances of a solar cell using the Lambert W-function", Sol Energy 2011; 85: 2386 - 2394.

12. Chatterjee A, Keyhani A, Kapoor D. "Identification of Photovoltaic Source Models", IEEE T Energy Conver 2011; 26: 883 - 889.

13. Arulmurugan, R\&Venkatesan, T, "Research and Experimental Implementation of a CV-FOINC Algorithm Using MPPT for PV Power System", Journal of Electrical Engineering and Technology, vol.10, no.1, pp. 30-40, 2015

14. Lun SX, Du CJ, Guo TT, Wang S, Sang JS, Li JP. "A new explicit I-V model of a solar cell based on Taylor's series expansion", Sol Energy 2013; 94: 221 - 232.

15. Soon JJ, KS Low. "Photovoltaic Model Identification Using Particle Swarm Optimization with Inverse Barrier Constraint", IEEE Trans. Power Electr 2012; 27: 3975 - 3983.

16. Arulmurugan, R, "Comparative evaluation of new FLC controller based MPPT for a DC to DC buck-boost zeta converter" WSEAS Transactions on power systems, vol.11, pp.27-34, 2016, E-ISSN: 2224-350X

17. Liu G, Nguang SK, Partridge A. "A general modeling method for I-V Conversion characteristics of geometrically and electrically configured photovoltaic arrays". $\quad$ Energy

Convers Manage 2011; 52: 3439 - 3445 . 
18. R.Arulmurugan, T.Anushalini, "Implementation of Fuzzy Controlling Structure of PV-FC for a Gird Connected System", 4th International conference on Electrical Energy Systems, Dept. of EEE, SSN College of Engineering, Kalavakkal, Chennai, 07-09 February 2018

19. R.Arulmurugan et al, "Improved Fractional Order VSS Inc-Cond MPPT algorithm for Photovoltaic Scheme", International Journal of Photoenergy, vol. 2014, Article ID 128327, 10 pages, 2014. DOI:10.1155/2014/128327. 